\title{
Practitioner-informed improvements to early childhood intervention performance checklists and practice guides
}

\author{
$*^{1}$ Carl J. Dunst; ${ }^{2}$ Deborah W. Hamby; ${ }^{3}$ Linda L. Wilson; ${ }^{4}$ Marilyn Espe-Sherwindt; \\ ${ }^{5}$ Donna E. Nelson \\ *Orelena Hawks Puckett Institute \\ 128 South Sterling Street Morganton, NC 28655 United States \\ *Email: cdunst@puckett.org
}

Submitted: 25 May 2017 | Revised: 25 July 2017 | Accepted: 27 July 2017

\begin{abstract}
Results from four early childhood practitioner field-tests of performance checklists and early intervention practice guides are reported. Findings from the first field-test were used to make changes and improvements in the checklists and practice guides were evaluated in the second and third field-tests, and findings from the latter two field-tests were used to improve the checklist and practice guide evaluated in the fourth field-test. The results indicated that changes made in response to practitioners' suggestions and feedback were associated with (1) progressive increases in the practitioners' social validity judgments of the checklists, practice guides, and checklistpractice guide correspondence; and (2) progressive decreases in the number of practitioner suggestions and feedback for improving the early intervention materials. The field-test research demonstrates the importance of practitioner input, suggestions, and feedback for improving the usefulness of early childhood intervention practices.
\end{abstract}

Keywords: early childhood intervention, performance checklists, practice guides, social validity, practitioner appraisals

\section{How to cite item:}

Dunst, C., Hamby, D., Wilson, L., Espe-Sherwindt, M., \& Nelson, D. (2017). Practitioner-informed improvements to early childhood intervention performance checklists and practice guides. REiD (Research and Evaluation in Education), 3(1), 12-27. doi:http://dx.doi.org/10.21831/reid.v3i1.14158

\section{Introduction}

Early childhood intervention for infants, toddlers, and preschoolers with identified disabilities or developmental delays and their families, as well as for young children who are at-risk for poor developmental outcomes for biological or environmental reasons is now common practice throughout the world (e.g., Farrell, Kagan, \& Tisdall, 2016; Groark, Eidelman, Maude, \& Kaczmarek, 2011; Guralnick, 2005; Odom, Hanson, Blackman, \& Kaul, 2003; Sukkar, Dunst, \& Kirkby, 2017). Early childhood intervention includes the experiences and learning oppor- tunities afforded young children to promote acquisition of functional behavior (Bailey \& Wolery, 1992; Dunst \& Espe-Sherwindt, 2017) and the supports and resources provided to or procured by parents and other family members to strengthen family functioning (Cowan, Powell, \& Cowan, 1998; Dunst, 2017b).

The field of early childhood intervention has a relatively short but rich history (Dunst, 1996; McLean, Sandall, \& Smith, 2016; Meisels \& Shonkoff, 2000). In the 50+ years since Hunt (1961) first noted that experiences early in a child's life could alter developmental outcomes, and later, that respon- 
sive caregiving was an important factor in shaping those outcomes (Hunt, 1987), considerable advances have been made in terms of understanding which experiences under which conditions have which kinds of outcomes and benefits (e.g., Britto, Engle, \& Super, 2013; Farrell et al., 2016; Odom \& Wolery, 2003; Reichow, Boyd, Barton, \& Odom, 2016). Early childhood intervention practitioners now have many choices and options in terms of the intervention practices they can use in their work with young children and their families.

Many factors influence practitioners' adoption and use of different kinds of early childhood intervention practices, including, but not limited to, personal beliefs about practice-outcome relationships and one's ability to use a practice competently and confidently (Bruder, Dunst, \& Mogro-Wilson, 2011; Trivette, Dunst, Hamby, \& Meter, 2012). These beliefs include the social validity appraisals of early childhood intervention practices and also their intended outcomes (Kazdin, 2005).

The practical importance of social validity appraisals is that these types of judgments can help explain why a practitioner does or does not use an intervention practice. Subjective judgments of the importance and acceptability of intervention goals, practices, and outcomes likely influence practitioners' adoption and use of different kinds of intervention procedures (Foster \& Mash, 1999). According to Strain et al. (2012), intervention practices are not likely to be used by practitioners (or parents) if the practices themselves are not viewed as socially valid and worth the time and also effort to use. Dunst, Raab, and Hamby (2016), for example, found parents' social validity judgments of interestbased child language learning practices were directly related to parents' fidelity of use of the practices and indirectly related to child language development mediated by fidelity of use of the practices.

The study described in this paper is part of a line of research and practice on (a) the development of evidence-informed early childhood intervention performance checklists and both practitioner and parent practice guides and (b) the influences of practitioner feedback and suggestions on the improvement of both sets of materials. The study involved four field-tests that solicited practitioner social validity judgments of selected checklists and practice guides as well as suggestions for the improvement of both products. Each field-test involved practitioner review and evaluation of a different performance checklist and a different practice guide where feedback and suggestions were used to inform improvements in both sets of products. The findings from the first field-test were used to make changes in the checklists and practice guides in the second and third field-tests, and findings from the latter two field-tests were used to inform improvements to the checklist and practice guide in the fourth field-test. Preliminary findings from this line of research and practice indicated that changes made to the checklists and practice guides in response to practitioner evaluations of the intervention materials were associated with stronger social validity appraisals of revised checklists and practice guides (Dunst, 2017a).

\section{Evidence-Informed Checklists and Practice Guides}

The performance checklists and practice guides that were the focus of field-test research were developed at the Early Childhood Technical Assistance Center at the University of North Carolina - Chapel Hill, United States (www.ectacenter.org). Checklists include lists of the key characteristics of a method or procedure that operationally defines the active ingredients of desired performance. Early childhood intervention checklists include the key characteristics of intervention practices that are used to produce observable changes or improvement in child or family functioning. Practice guides include descriptions of everyday intervention activities that can be used to affect changes in child or family functioning.

\section{Performance Checklists}

Early childhood intervention performance or procedural checklists provide concrete reminders for using intervention practices in a competent manner (Gawande, 2009; 
Wilson, 2013). The checklists were developed using a conceptualization-operationalizationmeasurement framework (Babbie, 2009; Dunst, 2017c; Dunst, Trivette, \& Raab, 2015) where research findings from primary research syntheses and reviews (Dunst, in preparation) informed checklist indicator selection or development. Performance checklists differ from other types of checklists by specifying a "list of tasks or steps required to complete a procedure [intervention practice] successfully" (Wilson, 2013, p. 4). According to Gawande (2009), these kinds of checklist indicators provide practitioners concrete reminders for how to implement an intervention practice consistently, reliably, and competently.

Twenty-nine performance checklists were developed by first using the Division for Early Childhood Recommended Practices (Division for Early Childhood, 2014) to identify internally consistent sets of practice indicators for different types of intervention practices where the final selection of checklist practice indicators were informed by research evidence. The checklists were all formatted in the same way because "applying organizations to new learning causes learners to focus on the meaning" [intent] of the checklist indicators (Schwartz, 2014, p. 107).

Each checklist includes (1) a brief description of a checklist practice and how the checklist can be used, (2) a list of evidenceinformed practice indicators, (3) a rating scale for doing a self-evaluation or coach-facilitated evaluation of the use of the practice indicators, and (4) space for recording notes about a practitioners' experience using the checklist practices. Appendix A shows the performance checklist that was the focus of practitioner evaluation in the fourth field-test. The reader is referred to Dunst (2017) for a more detailed description of the procedures used to develop the checklists.

\section{Practice Guides}

Two sets of practice guides were developed using the checklist indicators as the sources of intervention activities: One set for parents and other primary caregivers and a second set for early childhood intervention practitioners. The practice guides were also all formatted in the same way. Each practice guide includes: (1) a description of a practice and its intended outcome, (2) examples of activities for using a practice, (3) videos of parents or practitioners using the practice, (4) a vignette of parents or practitioners implementing a practice, (5) functional outcome indicators for determining if the practice had expected benefits, and (6) a link to external resources for additional ideas (activities) for using a practice. Appendix B shows the practice guide for the Family Capacity-Building Practices Checklist used in the fourth field-test. The practice guides are modeled after the ones that have been extensively field-tested and evaluated by parents, practitioners, technical assistance providers in previous research and intervention studies (e.g., Dunst, Masiello, Meter, Swanson, \& Gorman, 2010; Dunst, Trivette, Gorman, \& Hamby, 2010; Trivette, Dunst, \& Hamby, 2010).

\section{Hypotheses}

The analyses focused on two primary and two secondary hypotheses. The two primary hypotheses were:

$\mathrm{H}_{1:}$ : The social validity judgments of the performance checklists and practice guides will increase linearly as a result of changes and improvements made in response to practitioners' evaluations as evidenced by the sizes of effect for the linear increases and associated improvement indices.

$\mathrm{H}_{2}$ : The number of practitioner suggestions for improving the checklists and practice guides will decrease linearly as a result of changes and improvements made in response to practitioners' evaluations as evidenced by the sizes of effect for the linear increases and associated improvement indices. The two secondary hypotheses were:

$\mathrm{H}_{3}$ : The sizes of effects and improvement indices for Field-Test 1 vs. Field-Test 4 will be larger than those for Field-Tests $2+3$ vs. Field Test 4 as a result of the progressive changes and improvements made in response to practitioners' evaluations of the checklists and practice guides.

$\mathrm{H}_{4}$ : The sizes of effects and improvement indices for Field-Tests $1+2+3$ vs. 
Field-Test 4 will provide the best estimates of the cumulative changes made in response to practitioners' evaluations of the checklists and practice guides. Thus, the four hypotheses were tested by a priori linear and orthogonal contrasts for between-field-test comparisons in the analyses of the field-test research data.

\section{Method}

The participants consisted of 67 practitioners from an early head start program in one state and two early childhood intervention programs in other states. The three programs have a history of using innovative practices where the program practitioners are knowledgeable about contemporary evidenceinformed early childhood intervention practices. There were no between-group differences in the percentage of participants in the different field-test studies, $\chi^{2}=6.68, d f=6, p$ $=.3516$, and nor was there in the percentage of participants in the type of early childhood program in the field-tests, $\chi^{2}=2.77, d f=6, p$ $=.8375$.

Table 1. Background characteristics of the field-test participants

\begin{tabular}{lcc}
\hline \multicolumn{1}{c}{ Characteristics } & Number & Percent \\
\hline Education degree & 14 & 20 \\
AA & 24 & 35 \\
BA/BS & 26 & 40 \\
MA/MS & 3 & 5 \\
Ph.D/Ed.D & & \\
Discipline & 42 & 63 \\
Early childhood & 16 & 24 \\
Early childhood special & & \\
education/special education & 9 & 13 \\
Other & & \\
Years of experience & 4 & 6 \\
$<1$ & 13 & 19 \\
2-5 & 15 & 22 \\
6-10 & 10 & 15 \\
11-15 & 14 & 21 \\
16-20 & 11 & 16 \\
Primary practitioner role & & \\
Child-focused & 25 & 37 \\
Family-focused & 42 & 63 \\
\hline
\end{tabular}

Note: aSpeech and language pathologists, child and family specialists, early interventionists, and social workers/family workers.
The background characteristics of the participants are shown in Table 1 . The majority of practitioners $(75 \%)$ had either bachelor's or master's degrees. Most of the practitioners had degrees in early childhood education or early childhood special education/ special education. The participants' median years of experience ranged between 6 and 10 with $78 \%$ having from 6 to $20+$ years of experience. Nearly two-thirds of the participants worked primarily with parents and their children (family-focused) and 37\% worked primarily with children (child-focused). There were no between field-test differences for any of the participant background characteristics shown in Table $1, \chi_{\mathrm{s}}=0.17$ to $10.73, d f_{\mathrm{s}}=3$ to $15, p_{\mathrm{s}}=.1004$ to .9817 .

\section{Procedure}

The performance checklists and practice guides that were the focus of the field-test evaluations are shown in Table 2. The four topic areas included child, parent-child, parent, and family-focused intervention practices. Both the checklists and practice guides included different kinds of interventions for (a) using everyday activities as sources of child learning opportunities and (b) parent sensitivity and responsiveness to child behavior in the activities as the primary caregiver practice to reinforce child competencies and sustain child engagement in the activities.

The checklist in the first field-test included practice indicators for strengthening caregiver and child relationships that focused on bidirectional, reciprocal interactions between interactive partners (Eshel, Daelmans, Cabral de Mello, \& Martines, 2006). The practice guide for the checklist indicators included a number of different socially interactive games that caregivers could use to engage young children in your turn-my turn interactive episodes (e.g., Dunst, Pace, \& Hamby, 2007). 
Table 2. Performance checklists and practice guides that were the focus of practitioner social validity judgments and feedback

\begin{tabular}{clll}
\hline Field-test & \multicolumn{1}{c}{ Topic area } & \multicolumn{1}{c}{ Performance checklists } & \multicolumn{1}{c}{ Practice guides } \\
\hline 1 & Interaction & Adult-child interactions & Social games \\
2 & Environment & Natural learning opportunities & It's natural \\
3 & Instruction & Naturalistic instruction & Learning comes naturally \\
4 & Family & Family capacity-building & Everyday child learning \\
\hline
\end{tabular}

The checklist in the second field-test included indicators for identifying everyday activities that provide the most opportunities for child learning (Dunst, Bruder, Trivette, \& Hamby, 2006). The practice guide included ideas and strategies for engaging a child in the activities (Dunst, Raab, \& Trivette, 2013b). The checklist in the third field-test included indicators for using naturalistic teaching practices for reinforcing child behavior initiations and elaborations while engaged in everyday activities (Dunst, Raab, \& Trivette, 2011). The practice guide included different kinds of intervention activities and strategies for using natural reinforcing consequences for reinforcing child behavior (e.g., Dunst, Raab, \& Trivette, 2013a).

The checklist in the fourth field-test included methods for strengthening family capacity to provide a child everyday learning opportunities (Swanson, Raab, \& Dunst, 2011). The practice guide included a set of step-bystep instructions for practitioners to use to encourage and support parent-mediated everyday child learning (e.g., Raab, Dunst, \& Trivette, 2013).

The checklist and practice guide in the first field-test had not been subjected to prior review and feedback, and practitioner evaluations of both products were used as the baseline for evaluation of subsequent revisions and improvements to the checklists and practice guides in the second and third field-tests. The changes to the checklists in response to practitioner feedback and suggestions included clarifying the purpose of the checklist instructions and intended users (practitioners), rewording the checklist indicators to improve meaning and intent, clarifying how to use the checklist indicators to plan intervention sessions with parents, and the way how to use the rating scale to do a self-evaluation of how many and how well the checklist indicators were used with a child or parent. The changes to the practice guides included adding captions to the videos of parents or practitioners using the practices, adding additional intervention activities to the practice guides, including suggestions for making adaptations to the practice guide activities (where appropriate), and clarifying how to use the outcome indicators for evaluating the benefits of the practice guide activities.

Feedback and suggestions on the second and third field-tests were used to make additional changes to the checklist and practice guide in the fourth field-test. The changes to the checklist included clarifying the difference between using the checklist indicators for a priori intervention planning and doing a post hoc self-evaluation of the use of the indicators and clarifying the instructions for how to use the checklist indicators for completing a self-evaluation. The changes to the practice guide included additional specificity in terms of the focus and intent of the practice guide as well as the practice guide activities.

\section{Field-Test Survey}

The survey included four sections: (1) practitioner social validity judgments of the checklists, practice guides, and correspondence between practice guides and checklist indicators; (2) open-ended questions asking for suggestions to improve the checklists and practice guides; (3) levels of experience needed for a practitioner to understand and use checklists and practice guides; (4) background information about the field-test participants (Table 1). Each field-test involved an emailed invitation sent to the directors of each program that included instructions for participation in the field-tests, PDFs of the checklists and practice guides, and a URL link to the survey. The program directors were asked to forward the emailed invitation to their staff. Participation in the field-tests was voluntary, 
and the field-test research was considered exempt from human subjects review because practitioners were asked only to evaluate materials designed for routine early childhood intervention. The surveys were completed online using Qualtrics Survey Soft-ware.

The social validity items for the performance checklists, practice guides, and checklist-practice guide correspondence (four per each section) were developed by using Foster and Mash's (1999) framework for developing indicators for measuring the importance and acceptability of intervention practices and outcomes. In addition, the social importance of the checklists and practice guides was measured in terms of the subjective value attributed to the intervention materials (e.g., The checklist items are easy to understand and follow; The practice guide activities would be engaging to most children). The social acceptability of the checklists and practice guides was measured in terms of judgments about the fit of the practices to everyday life (e.g., The checklist indicators would be easy to use with a parent or child; The practice guide would be worth my time and effort to use). The social validity items were each rated on a 5-point scale ranging from Do Not Agree At All (with the survey items) to Agree a Great Deal (with the survey items). The items were adopted from the ones used in field-tests of other intervention practices (e.g., Dunst et al., 2007; Dunst, Trivette, et al., 2010).

The principal component factor analysis of the three sets of items in each field-test with orthogonal rotation each produced a single-factor solution indicating that summated scores were warranted as measures of social validity judgments (Spector, 1992). The average coefficient alpha for the checklist indicators was .89 (Range $=.81$ to .97$)$, the average alpha for the practice guide indicators was .85 (Range $=.77$ to .91 ), and the average alpha for the correspondence between the checklists and practice guides was .92 (Range $=.85$ to .95). The alpha's in all 12 factor analyses reached acceptable levels of internal reliability (Nunnally \& Bernstein, 1994).

The open-ended questions for improving the checklists asked for suggestions about the (1) checklist instructions, (2) checklist indicators, (3) self-evaluation scale, and (4) any other suggestions for improvement. The open-ended questions for improving the practice guides asked for suggestions about the (1) practice guide format, (2) practice guide activities, (3) videos of the practices, (4) child outcomes, and (5) any other suggestions to improve the practice guides.

\section{Methods of Analysis}

The 3 Between Field Test ANOVAs with preplanned linear and between group contrasts were used to evaluate the effects of changes to the checklists and practice guides on participants' social validity judgments. The independent variable was the different fieldtests (Field-Test 1 vs. Field-Tests $2+3$ vs. Field-Test 4). The linear contrasts and between-field-test comparisons permitted tests of the four study hypotheses. The dependent measures in three ANOVAs were the summated social validity scores for the performance checklists, practice guides, and correspondence between the checklists and practice guides.

The primary metrics for testing the study hypotheses were Cohen's $d$ effect sizes and associated improvement indices (What Works Clearinghouse, 2014). Effect sizes rather than statistical significance testing is the preferred metric for substantive interpretation because effect sizes and not $p$-values are the best estimates of the magnitude of the differences between two groups or contrasts (Coe, 2002). As a general rule, effect sizes between .20 and .49 are considered small, those between .50 and .79 are considered medium, those between .80 and 1.19 are considered large, and effect sizes equal to or greater than 1.20 are considered very large. Improvement indices are measures of the practical importance of the changes made to the checklists and practice guides (Durlak, 2009). The indices convert effect sizes into a percentile change (gain) score by a target group. These indices vary from -50 to 50 where a positive difference between later and earlier field-tests provides a measure of the amount of improvement that occurred as a result of changes made to the checklists and practice guides. ZCalc was used to evaluate the improvement indices (Neill, 2006). 
Primary analyses of the practitioners' social validity judgments were supplemented by computing the percent of indicators rated a 4 or 5 on the 5 -point scale to ascertain the overall levels of agreement with the indicators. As found in consumer sciences research, the larger the percent of indicators rated a 4 or 5 on a 5 -point scale, the stronger the endorsement of a product, practice, or service (Mackiewicz \& Yeats, 2014; Reichheld, 2003). The Mantel-Haenszel test for linear trends was used to determine if there were progressive increases in the percent of practitioners rating the social validity items a 4 or 5 from the first to fourth field-tests (SPSS Inc., 2005).

The effects of the changes made to the checklists and practice guides in response to practitioner suggestions were tested by both 3 Between Field-Test ANOVAs for the total number of practitioner suggestions and by 3 Between Field-Test Chi-Square analyses for dichotomous responses for each open-ended section. The same linear contrasts for the social validity appraisals were made for evaluating changes in the practitioner suggestions.

\section{Findings and Discussion}

\section{Social Validity Judgments}

Figure 1 shows the mean social validity scores for four field-tests for each set of importance and acceptability judgments. The 3 between field-test ANOVAs produced between group differences for the practitioner social validity judgments of the performance checklists, $F(2,64)=3.49, p=.0364$, and checklist/practice guide correspondence, $F(2$, $64)=4.94, p=.0101$, but not for the practice guides, $F(2,64)=0.42, p=.6562$.

The results for linear contrasts and between-field-test comparisons are presented in Table 3. There were small linear increases to the practice guides to medium linear increases to both performance checklists and checklist/ practice guide correspondence increases from the first to fourth field-tests as evidenced by the sizes of effect for the linear trends. The effect sizes were associated with improvement indices of 9, 22, and 27 percent, respectively, in response to the progressive changes in the practice guides, checklists, and correspondence comparisons. The findings are consistent with Hypothesis 1 that changes made in response to the practitioners' feedback and suggestions would be related to improvements in the social validity judgments of the checklists and practice guides.

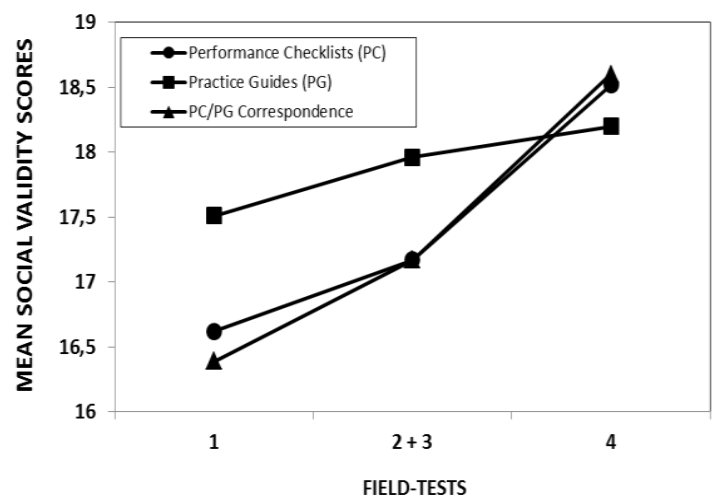

Figure 1. Mean practitioner social validity scores for the four field-tests.

Table 3. Linear contrasts and between-field-test comparisons and associated significance levels, effect sizes, and improvement indices

\begin{tabular}{lllll}
\hline \multirow{2}{*}{ Product } & \multirow{2}{*}{ Linear trend } & \multicolumn{3}{c}{ Field-test comparisons } \\
\cline { 3 - 5 } & & $\mathbf{1}$ vs. 4 & $\mathbf{2 + 3}$ vs. 4 & $\mathbf{1 + 2 + 3}$ vs. 4 \\
\hline Statistical significance & & & & \\
Performance checklists (PC) & $p=.0107$ & $p=.0040$ & $p=.1410$ & $p=.0052$ \\
Practice guides (PG) & $p=.1802$ & $p=.1845$ & $p=.2908$ & $p=.2090$ \\
PC/PG correspondence & $p=.0025$ & $p=.0012$ & $p=.1706$ & $p=.0014$ \\
Cohen's $\boldsymbol{d}$ effect sizes & & & & \\
Performance checklists (PC) & 0.59 & 0.93 & 0.22 & 0.67 \\
Practice guides (PG) & 0.23 & 0.29 & 0.18 & 0.21 \\
PC/PG correspondence & 0.74 & 1.09 & 0.33 & 0.78 \\
Improvement indices & & & & \\
Performance checklists (PC) & 22 & 32 & 9 & 25 \\
Practice guides (PG) & 9 & 11 & 7 & 8 \\
PC/PG correspondence & 27 & 36 & 13 & 28 \\
\hline
\end{tabular}

Note: Both the linear trends and field-test comparisons all have numerator degrees of freedom $=1$. 
There were small (practice guides) to large (checklists and checklist/practice guide correspondence) effect sizes for the differences between the Field-Test 1 vs. Field-Test 4 social validity judgments (Table 3 ). These were associated with improvement indices of 11, 32, and 36 percent, respectively, for the practice guides, checklists, and correspondence judgments. The effect sizes for the FieldTests $2+3$ vs. Field-Test 4 for the betweenfield-test comparisons were small for both the performance checklists and checklists/practice guides correspondence. The betweenfield-test comparisons were associated with improvement indices of $9 \%$ for the checklist differences and 13\% for the checklist/practice guide correspondence differences. The comparisons of the two sets of results in Table 3 shows, as hypothesized, that the sizes of effect and associated improvement indices for Field-Tests 1 vs. 4 are considerably larger than those for Field-Tests $2+3$ vs. 4 .

The cumulative effects of the progressive changes made in response to the practitioner evaluations are evidenced from the Field-Tests $1+2+3$ vs. Field-Test 4 comparisons. There were small (practice guides) to medium (checklists and checklists/practice guides correspondence) effect sizes for these between-field-test comparisons. The effect sizes were associated with improvement indices of 8,25 , and 28 percent, respectively. The results are consistent with the hypothesized relationships between changes made in response to practitioner feedback and suggestions and improvements in the social validity judgments of the intervention practices.

The percent of social validity items rated a 4 or 5 on each section of the survey for the different field-tests are shown in Figure 2. There were linear increases in the percent of indicators rated a 4 or 5 for the performance checklists, $\chi=9.04, d f=1, p=$ $.003, d=.79$, practice guides, $\chi^{2}=5.88, d f=1$, $p=.015, d=.62$, and checklist/practice guide correspondence, $\chi^{2}=10.98, d f=1, p=.001, d$ $=.97$. The effect sizes for the linear trends were medium to large and associated with improvement indices of 29, 23, and 33 percent, respectively. The smaller effect size for the linear increase in the social validity ratings of the practice guides was not unexpected given the fact that practitioner judgments of the practice guides were higher than those for the checklist on the first three field-tests. As shown in Figure 2, 98\% to $99 \%$ of the social validity items received the highest two ratings in the fourth field-test which are noticeably higher than that in the other three field-tests.

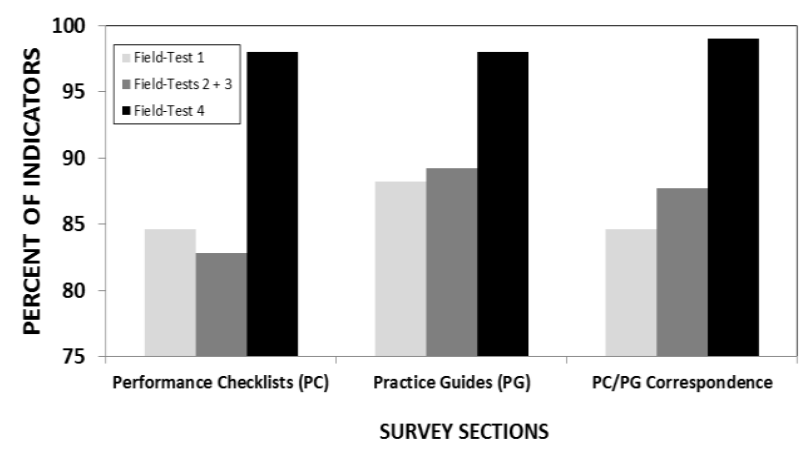

Figure 2. Percent of social validity items judged as acceptable and important by the field-test participants

Practitioner Suggestions

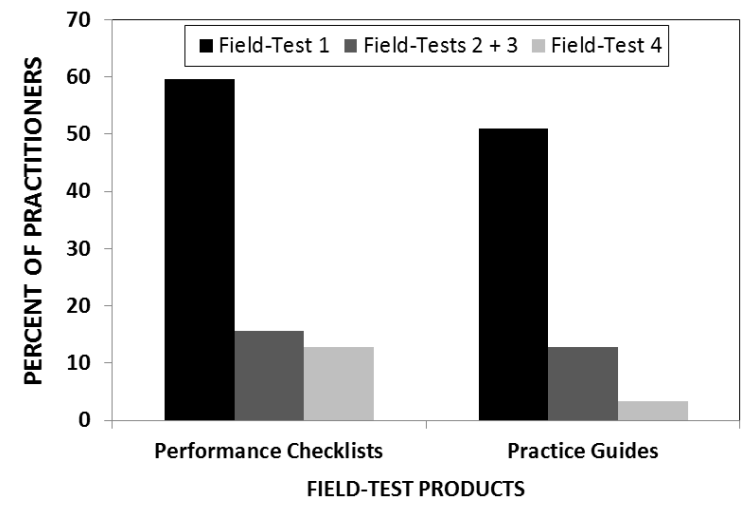

Figure 3. Percent of practitioners making suggestions for improving the performance checklists and practice guides

Figure 3 shows the percent of practitioners who made suggestions for improving the checklists and practice guides in the different field-tests. The 3 between-field-test ANOVAs for the total number of practitioner suggestions produced between field-test differences for both the performance checklists, $F(2,64)=7.11, p=.0016$, and practice guides, $F(2,64)=10.51, p=.0001$. There 
were linear decreases in the number of suggestions for the checklists, $F(1,64)=11.41, p$ $=.0012, d=.85$, and practice guides, $F(1,64)$ $=18.31, p=.0001, d=1.07$. Both sizes of effects were large for the linear decreases in the number of practitioner suggestions. The effect sizes were associated with the improvement indices of $30 \%$ and $36 \%$ respectively. The patterns of results are consistent with the hypothesis that the practitioners would suggest fewer changes as a function of improvements made in response to their feedback and suggestions.

Further examination of the suggestions for improving the checklists found linear decreases in the percent of practitioners who made suggestions for changes to the checklist instructions, $\chi^{2}=6.43, d f=1, p=.011, d=$ .77 , the checklist indicators, $\chi^{2}=6.96, d f=1, p$ $=.008, d=.83$, and the self-evaluating rating scale, $\chi^{2}=2054, d f=1, p=.0555, d=.45$. The sizes of effects were medium, large, and small, respectively, and associated with improvement indices between $17 \%$ and 30\%. There were also linear decreases in the percent of practitioners making suggestions to improve the practice guide format, $\chi^{2}=12.43$, $d f=1, p=.0000, d=1.15$, practice guide activities, $\chi^{2}=9.49, d f=1, p=.001, d=.87$, practice guide outcome statements, $\chi^{2}=2.06$, $d f=1, p=.051, d=.38$, and videos of parents or practitioners using the practices, $\chi^{2}=17.17$, $d f=1, p=.0000, d=1.36$. The effect sizes were small to very large and associated with improvement indices between $15 \%$ and $41 \%$. These findings, taken together, further support hypothesized relationships between the changes made in response to the practitioners' evaluations of the checklists and practice guides and fewer suggestions for improving the intervention practices.

\section{Discussion}

The findings provide support for the two primary hypotheses that changes made to the performance checklists and practice guides in response to early childhood practitioners feedback and suggestions would be related to the study outcomes. The results showed that practitioners' social validity ratings increased as a function of the improve- ments to both the performance checklists and practice guides and also to the checklist/practice guide correspondence. The results also showed that there were fewer suggestions for making changes to the checklists and practice guides as a function of using practitioner feedback to improve both sets of products.

The patterns of results also provide support for the two secondary hypotheses. The sizes of effect for the first vs. fourth field-tests were larger than those for the second and third vs. fourth field-tests (Table 3). These results were expected because fewer suggestions for changes to the checklists and practice guides were made on the second and third field-tests compared to the first field-test (Figure 3). The cumulative effects for the changes made in response to practitioners' suggestions were evidenced by the sizes of effect for the first three field-tests vs. the fourth field-test. Both the effect sizes for these comparisons and improvement indices (Table 3) indicated that the progressive sets of changes made in response to practitioners' suggestions were associated with the highest social validity rating (Figure 1) and fewest suggestions for change (Figure 3) on the fourth field-test.

The fact that the effect sizes and improvement indices for the practice guides were smaller than those for the performance checklists and checklist-practice guide correspondence deserves comment in order to place the results in empirical context. The practice guides were modeled after the ones that had previously been field-tested with parents and practitioners where the results were used to improve the intervention materials (e.g., Dunst, Trivette, et al., 2010; Trivette, Dunst, Masiello, Gorman, \& Hamby, 2009). It was therefore not unexpected that the majority of social validity indicators for the practice guides on the first three field-tests were higher than those for the checklists and checklistpractice guide correspondence (Figure 3). This was the case because the practice guide format and content were informed by lessons learned in previous research and practice.

The focus on the social validity of the performance checklists and practice guides was based on research indicating that subjective judgments of the importance and accept- 
ability of intervention practices and outcomes are related to both adoption and fidelity of use of the practices (e.g., Dunst et al., 2016; Strain et al., 2012; Trivette, Raab, \& Dunst, 2014; Wainer \& Ingersoll, 2013; Wehby, Maggin, Moore Partin, \& Robertson, 2011). As noted by Strain et al. (2012), these "likingimplementation with fidelity relationships" ( $\mathrm{p}$. 197) are important because they help explain at least the likelihood of early childhood intervention practices being used as intended.

\section{Conclusion and Suggestions}

The study described in this paper has both strengths and limitations. One strength is the fact that the procedures used to inform changes in the checklists and practice guides illustrates how the consumer level input can be used to improve social validity appraisals of the intervention materials constituting the focus of evaluation. Another strength is establishing the inverse relationship between increases in social validity ratings and concomitant decreases in practitioner suggestions for changes. In another set of analyses in this line of research and practice, practitioners' cognitive judgments of the performance checklists and practice guides were the only variable accounting for variations in the social validity ratings of the intervention materials (Dunst \& Hamby, 2017).

One limitation of the study is that the field-tests were conducted in only three early childhood intervention programs. Therefore, it is not known if practitioners in other early childhood intervention programs would judge the checklists and practice guides in the same or different ways. Another limitation is the fact that only 4 out of 29 performance checklists and only 4 out of 67 practice guides were evaluated in the field-tests. Whether other checklists and practice guides would be judged similarly is therefore not known.

Advances in our understanding of the role social validity judgments play in practitioners' and parents' use of different kinds of early childhood intervention has broadened our knowledge of the antecedents for and conditions under which intervention practices are used with fidelity (Leko, 2014; Strain et al., 2012). One simple way of assessing practi- tioners' and parents' social validity appraisals is to ask the question "Was using XYZ practice worth your time and effort or was it more trouble than it was worth?" If a practitioner or parent responds that it was not worth the trouble to use, it is unlikely that the practice will be used with fidelity or used at all.

Although the field-test process was used to inform improvements in early childhood intervention performance checklists and practice guides, the process itself could easily be used in other fields for achieving performance excellence. This is especially the case in professions where there needs to be practitioner buy-in to ensure actual performance mirrors desired performance.

\section{Acknowledgements}

The field-test research described in this paper was supported, in part, by a subcontract to the Orelena Hawks Puckett Institute from the Early Childhood Technical Assistance (ECTA) Center, Frank Porter Graham Child Development Institute, University of North Carolina--Chapel Hill. The ECTA Center is funded by the U.S. Department of Education, Office of Special Education Programs (Grant \#H326P120002). The opinions expressed, however, are those of the authors and no endorsement by the funder, University, or ECTA Center should be implied or inferred.

Special thanks to the practitioners who participated in the field-test evaluations and for providing assessments of and feedback on the performance checklists and practice guides.

\section{References}

Babbie, E. R. (2009). The practice of social research (12th ed.). Belmont, CA: Wadsworth.

Bailey, D. B., Jr., \& Wolery, M. (1992). Teaching infants and preschoolers with disabilities (2nd ed.). Upper Saddle River, NJ: Merrill.

Britto, P. R., Engle, P. L., \& Super, C. M. (Eds.). (2013). Handbook of early childhood development research and its impact on global policy. New York, NY: Oxford. 
Bruder, M. B., Dunst, C. J., \& Mogro-Wilson, C. (2011). Confidence and competence appraisals of early intervention and preschool special education practitioners. International Journal of Early Childhood Special Education, 3(1), 13-37.

Coe, R. (2002, September). It's the effect size, stupid: What effect size is and why it is important. Paper presented at the Annual Conference of the British Educational Research Association, University of Exeter, England. Retrieved from http://www.leeds.ac.uk/educol/docum ents/00002182.htm.

Cowan, P. A., Powell, D., \& Cowan, C. P. (1998). Parenting interventions: A family systems perspective. In W. Damon, I. E. Sigel, \& K. A. Renninger (Eds.), Handbook of child psychology: Vol. 4. Child psychology in practice (5th ed., pp. 3-72). New York, NY: Wiley.

Division for Early Childhood. (2014). DEC recommended practices in early intervention/ early childhood special education. Retrieved from http://www.dec-sped.org/recom $\underline{\text { mendedpractices }}$

Dunst, C. J. (1996). Early intervention in the USA: Programs, models, and practices. In M. Brambring, H. Rauh, \& A. Beelmann (Eds.), Early childhood intervention: Theory, evaluation, and practice (pp. 11-52). Berlin, Germany: de Gruyter.

Dunst, C. J. (2017a). Early childhood practitioner judgments of the social validity of performance checklists and parent practice guides. Journal of Education and Training Studies, 5(3), 176187. Retrieved from http:// redfame.com/journal/index.php/jets/a rticle/view/2162 doi:10.11114/jets.v5i3.2162

Dunst, C. J. (2017b). Family systems early childhood intervention. In H. Sukkar, C. J. Dunst, \& J. Kirkby (Eds.), Early childhood intervention: Working with families of young children with special needs (pp. 3860). Abingdon, Oxfordshire: Routledge.
Dunst, C. J. (2017c). Procedures for developing evidence-informed performance checklists for improving early childhood intervention practices. Journal of Education and Learning, 6(3), 1-13. Retrieved from http://www.ccsenet.org Ljournal/index.php/jel/article/view/66 $\underline{005}$ doi:10.5539/jel.v6n3px

Dunst, C. J. (in preparation). Research foundations for evidence-informed early childhood intervention performance checklists.

Dunst, C. J., Bruder, M. B., Trivette, C. M., \& Hamby, D. W. (2006). Everyday activity settings, natural learning environments, and early intervention practices. Journal of Policy and Practice in Intellectual Disabilities, 3, 3-10. doi:10.1111/j.17411130.2006.00047.x

Dunst, C. J., \& Espe-Sherwindt, M. (2017). Contemporary early intervention models, research, and practice for infants and toddlers with disabilities and delays. In J. M. Kauffman, D. P. Hallahan, \& C. P. Pullen (Eds.), Handbook of special education (2nd ed., pp. 831-849). New York, NY: Routledge.

Dunst, C. J., Masiello, T., Meter, D., Swanson, J., \& Gorman, E. (2010). Technical assistance providers' evaluation of the Center for Early Literacy Learning practice guides. CELLpapers, 5(3), 1-4. Retrieved from http://www.early literacylearning.org/cellpapers/cellpape rs v5n3.pdf

Dunst, C. J., Pace, J., \& Hamby, D. W. (2007). Evaluation of the Games for Growing tool kit for promoting early contingency learning. Asheville, NC: Winterberry Press.

Dunst, C. J., Raab, M., \& Hamby, D. W. (2016). Interest-based everyday child language learning. Revista de Logopedia, Foniatria y Audiologia, 36, 153-161. doi:10.1016/j.rlfa.2016.07.003

Dunst, C. J., Raab, M., \& Trivette, C. M. (2011). Characteristics of naturalistic language intervention strategies. Journal of Speech-Language Pathology and Applied 
Behavior Analysis, 5(3-4), 8-16. Retrieved from http://www.baojournal.com/SLP -ABA\%20WEBSITE/index.html

Dunst, C. J., Raab, M., \& Trivette, C. M. (2013a). Getting in step with responsive teaching. Everyday Child Language Learning Tools, Number 5, 1-4. Retrieved from http://www.puckett.org/CECLL $\angle$ ECLLTools 5.pdf

Dunst, C. J., Raab, M., \& Trivette, C. M. (2013b). Methods for increasing child participation in interest-based language learning activities. Everyday Child Language Learning Tools, Number 4, 1-6. Retrieved from http://www.puckett.org LCECLL/ECLLReport 7 LearnOps.p df

Dunst, C. J., Trivette, C. M., Gorman, E., \& Hamby, D. W. (2010). Further evidence for the social validity of the Center for Early Literacy Learning practice guides. CELLpapers, 5(1), 1-3. Retrieved from http://www.earlyliteracylearning.org/ce llpapers/cellpapers v5n1.pdf

Dunst, C. J., Trivette, C. M., \& Raab, M. (2015). Utility of implementation and intervention performance checklists for conducting research in early childhood education. In O. N. Saracho (Ed.), Handbook of research methods in early childhood education: Vol. 1. Research methodologies (pp. 247-276). Charlotte, NC: Information Age Publishing.

Durlak, J. A. (2009). How to select, calculate, and interpret effect sizes. Journal of Pediatric Psychology, 34(9), 917-928. doi:10.1093/jpepsy/jsp004

Eshel, N., Daelmans, B., Cabral de Mello, M., \& Martines, J. (2006). Responsive parenting: Interventions and outcomes. Bulletin of the World Health Organization, 84(12), 991-998. doi:10.1590/S004296862006001200016

Farrell, A., Kagan, S. L., \& Tisdall, E. K. M. (Eds.). (2016). The SAGE handbook of early childhood research. Thousand Oaks, CA: SAGE Publishing.
Foster, S. L., \& Mash, E. J. (1999). Assessing social validity in clinical treatment research issues and procedures. Journal of Consulting and Clinical Psychology, 67, 308-319. doi:10.1037/0022006X.67.3.308

Gawande, A. (2009). The checklist manifesto: How to get things right. New York, NY: Metropolitan Books.

Groark, C. J., Eidelman, S. M., Maude, S., \& Kaczmarek, L. (2011). Early childhood intervention: Shaping the future for children with special needs and their families. Santa Barbara, CA: Praeger.

Guralnick, M. J. (Ed.) (2005). The developmental systems approach to early intervention. Baltimore, MD: Brookes.

Hunt, J. M. (1961). Intelligence and experience. New York, NY: Ronald Press.

Hunt, J. M. (1987). The effects of differing kinds of experiences in early rearing conditions. In I. Uzgiris \& J. M. Hunt (Eds.), Infant performance and experience (pp. 39-97). Urbana, IL: University of Illinois Press.

Kazdin, A. E. (2005). Social validity. In B. S. Everitt \& D. C. Howell (Eds.), Encyclopedia of statistics in behavioral science (Vol. 4, pp. 1875-1876). Chichester, England: John Wiley \& Sons.

Leko, M. M. (2014). The value of qualitative methods in social validity research. Remedial and Special Education, 35(5), 275286. doi:10.1177/0741932514524002

Mackiewicz, J., \& Yeats, D. (2014). Product review users' perceptions of review quality: The role of credibility, informativeness, and readability. IEEE Transactions on Professional Communication, 57(4), 309-324. doi:10.1109/TPC.2014.2373891

McLean, M., Sandall, S. R., \& Smith, B. J. (2016). A history of early childhood education. In B. Reichow, B. A. Boyd, E. E. Barton, \& S. L. Odom (Eds.), Handbook of early childhood special education 
(pp. 3-20). Switzerland: Springer International.

Meisels, S. J., \& Shonkoff, J. P. (2000). Early childhood intervention: A continuing evolution. In J. P. Shonkoff \& S. J. Meisels (Eds.), Handbook of early childhood intervention (2nd ed., pp. 3-31). Cambridge, England: Cambridge University Press.

Neill, J. (2006). ZCalc: For converting a standardised mean effect size (ES) into a $z$ score and in expressing various ways (Version 0.1). Retrieved from www.wilderdom. com/research/ZCalc.xls

Nunnally, J. C., \& Bernstein, I. H. (1994). Psychometric theory (3rd ed.). New York, NY: McGraw-Hill.

Odom, S. L., Hanson, M. J., Blackman, J. A., \& Kaul, S. (2003). Early intervention practices around the world. Baltimore, MD: Brookes.

Odom, S. L., \& Wolery, M. (2003). A unified theory of practice in early intervention/early childhood special education: Evidence-based practices. Journal of Special Education, 37, 164-173. doi:10.1177/00224669030370030601

Raab, M., Dunst, C. J., \& Trivette, C. M. (2013). Adult learning procedure for promoting caregiver use of everyday child language learning practices. Everyday Child Language Learning Reports, Number 3, 1-9. Retrieved from http://www.cecll.org/download/ECLL Report 3 AdultLearning.pdf

Reichheld, F. F. (2003). The one number you need to grow. Harvard Business Review, 81(12), 46-54.

Reichow, B., Boyd, B. A., Barton, E. E., \& Odom, S. L. (Eds.). (2016). Handbook of early childhood special education. Switzerland: Springer International.

Schwartz, B. L. (2014). Memory: Foundations and applications (2nd ed.). Los Angeles, CA: SAGE.
Spector, P. E. (1992). Summated rating scale construction: $A n$ introduction. Newbury Park, CA: Sage.

SPSS Inc. (2005). SPSS 14.0. Statistical package for the social sciences. Chicago, IL: Author.

Strain, P. S., Barton, E. E., \& Dunlap, G. (2012). Lessons learned about the utility of social validity. Education and Treatment of Children, 35, 183-200. doi:10.1353/etc.2012.0007

Sukkar, H., Dunst, C. J., \& Kirkby, J. (Eds.). (2017). Early childhood intervention: Working with families of young children with special needs. Abingdon, Oxfordshire: Routledge.

Swanson, J., Raab, M., \& Dunst, C. J. (2011). Strengthening family capacity to provide young children everyday natural learning opportunities. Journal of Early Childhood Research, 9, 66-80. doi:10.1177/1476718X10368588

Trivette, C. M., Dunst, C. J., \& Hamby, D. W. (2010). Acceptability and importance of adaptations to literacy learning practices for young children with disabilities. CELLpapers, 5(4), 1-4. Retrieved from http://www.earlyliteracylearning.org/ce llpapers/cellpapers v5n4.pdf

Trivette, C. M., Dunst, C. J., Hamby, D. W., \& Meter, D. (2012). Research synthesis of studies investigating the relationships between practitioner beliefs and adoption of early childhood intervention practices. Practical Evaluation Reports, 4(1), 1-19. Retrieved from http://www.puckett.org/Practical $\% 20$ Evaluation\%20reports/CPE Report V ol4No1.pdf

Trivette, C. M., Dunst, C. J., Masiello, T., Gorman, E., \& Hamby, D. W. (2009). Social validity of the Center for Early Literacy Learning parent practice guides. CELLpapers, 4(1), 1-4. Retrieved from http://www.earlyliteracylearning. org/cellpapers/cellpapers v4n1.pdf

Trivette, C. M., Raab, M., \& Dunst, C. J. (2014). Factors associated with Head Start staff participation in classroom- 
based professional development. Journal of Education and Training Studies, 2(4), 3245. doi:10.11114/jets.v2i4.449

Wainer, A., \& Ingersoll, B. (2013). Intervention fidelity: An essential component for understanding ASD parent training research and practice. Clinical Psychology: Science and Practice, 20(3), 335-357. doi:10.1111/cpsp.12045

Wehby, J. H., Maggin, D. M., Moore Partin, T. C., \& Robertson, R. (2011). The impact of working alliance, social validity, and teacher burnout on implementation fidelity of the Good
Behavior Game. School Mental Health, 4(1), 22-33. doi:10.1007/s12310-0119067-4

What Works Clearinghouse. (2014). What Works Clearinghouse procedures and standards handbook. Washington, DC: U. S. Department of Education, Institute of Education Sciences. Retrieved from http://ies.ed.gov/ncee/wwc/pdf/refer ence resources/wwc procedures v3 0 standards handbook.pdf.

Wilson, C. (2013). Credible checklists and quality questionnaires: A user-centered design method. Waltham, MA: Morgan Kaufman. 


\section{Appendix A}

Early childhood intervention performance checklist

\section{Family Capacity-Building Practices Checklist}

This checklist includes practices for promoting parents' and other family members' use of child-level interventions to enhance child learning and development in ways that strengthen parenting confidence and competence. The capacity-building practices are used by a practitioner to promote a parent's understanding and use of everyday activities as sources of child learning opportunities
The checklist indicators can be used by a practitioner to plan intervention sessions with parents and other family members. The checklist rating scale also can be used to do a self-evaluation to determine if practitioner capacitybuilding practices actively involved parents in providing their children everyday learning opportunities

Practitioner: Child

Date:

Please indicate which practice characteristics you were able to use as part of parent and family member involvement in providing child learning opportunities:

$\begin{array}{cccc}\begin{array}{c}\text { Seldom } \\ \text { or Never }\end{array} & \begin{array}{r}\text { Some of } \\ \text { the Time }\end{array} & \begin{array}{c}\text { As Often } \\ \text { As I Can }\end{array} & \begin{array}{c}\text { Most of } \\ \text { the Time }\end{array} \\ (0-25 \%) & (25-50 \%) & (50-75 \%) & (75-100 \%)\end{array}$

Notes

1. Describe the use and benefits of everyday activities as sources of child learning opportunities

2. Illustrate or demonstrate child engagement in a variety of everyday activities

3. Describe and illustrate the importance of child interests and preferences for promoting child learning

4. Use an everyday activity checklist to have a parent select which activities would be easiest for the parent to use

5. Together with the parent, engage the child in a familiar everyday activity

6. Illustrate or demonstrate how adult responsiveness to child behavior is used to promote child learning in everyday activities

7. Provide supportive guidance, feedback, and suggestions to the parent throughout the capacity-building activities

8. Together with the parent, identify five or six everyday activities that will be used as child learning opportunities

9. Engage the parent in conversations about which activities will be used for child learning and which parent responses will be used to promote learning 


\section{Appendix B}

Early childhood intervention practice guide

\section{Everyday Child Learning Opportunities}

Family capacity-building practices are used to support and strengthen parents and other caregivers' abilities to provide their children everyday learning opportunities. This is accomplished using a number of different strategies for supporting and strengthening parents' use of everyday activities to promote child learning and development.

\section{Learning Guide: Family-Provided Child Learning Opportunities this Learning Guide}

- Parents are more likely to use intervention practices with their children if they understand the benefits of everyday child learning opportunities. Begin by explaining both the purpose and goal of the learning opportunities and the specific benefits to young children.

- Illustrate or demonstrate how to engage a child in everyday learning activities. Video vignettes of parents providing their children everyday learning opportunities generally work best. Be sure to point out the key characteristics of the practices

- Engage the parents in real-life (authentic) activities to provide their children everyday learning opportunities. The more familiar and routine the activities are to parents, the more likely they will feel confident using the activities as sources of child learning opportunities.

- Focus on two important child and parent behaviors as part of everyday child learning opportunities. The first is the importance of child interests and preferences as factors increasing child engagement in everyday activities The second is the role parents' responsiveness to child behavior

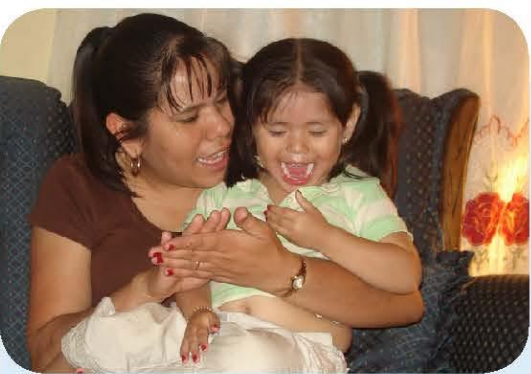
in everyday activities plays in supporting child learning

- Provide parents supportive guidance and feedback during and after parents' use of everyday learning opportunities with their child. Point out which characteristics of the practice were used by the parents and describe the child benefits of the practices

- Engage the parents in conversations, discussions, or review of their confidence using the practices. Provide specific positive comments, feedback, and suggestions in response to parents' descriptions to reinforce their sense of confidence.

- Jointly identify four or five everyday activities that the parents can use to provide learning opportunities for their child. The best activities are ones that provide the child multiple opportunities to engage in interactions with people, toys, and other materials.

- Identify things you can do to provide the parents regular ongoing support to encourage the continued use of the practices. It is important to plan to take time together to review and evaluate the learning opportunities to decide which activities should be continued, modified, and added. have used everyday activities to encourage their young children to make sounds and "talk more." She points out the children's high level of interest in the activities and how the parents' imitation of their children's sounds gets the children to continue making the sounds. At the therapist's next visit, Emma says that Felicity now "talks up a storm" while she plays lap games with her daughter. The therapist asks Emma to show her what this looks like and suggests trying to do the same thing in a few more activities. It isn't long before Emma identifies more than a dozen activities during which she can encourage her daughter to make more sounds.

You'll know the practice is working if ...

- Lots of everyday activities are used for child learning

- Parents are responsive to their children's behavior in the activities

- The children are interacting with people and objects in the activities

A Quíck Peek Felicity is a 3-year-old with multiple disabilities. Her mother, Emma, tells her daughter's speech therapist that Felicity is beginning to show increased interest in looking at other people and is making more sounds than usual. Mom asks the therapist about the best times to work on her daughter's speech. The therapist describes how there are many opportunities throughout the day that can be used to encourage Felicity to use sounds in interactions with mom, dad, and other family members. The therapist uses video she has stored 0 tablet computer to show Felicity's mom and dad how other parents 